\title{
The role of endogenous intoxication in pathogenetic mechanisms of heat stress in cattle
}

\author{
Ekaterina Rud $^{1}$, Elena Kuzminova ${ }^{1}$, Marina Semenenko ${ }^{1 *}$, Ksenia Semenenko ${ }^{1}$, and \\ Andrey Abramov ${ }^{1}$ \\ ${ }^{1}$ Krasnodar Research Center for Animal Husbandry and Veterinary Medicine, Pervomaiskaya st. 4, \\ 350055, Krasnodar, Russia
}

\begin{abstract}
The article presents the results of studies to identify the role of endogenous intoxication in the pathogenetic mechanisms of heat stress in cows in a comparative aspect between healthy animals and animals with hepatopathology. The obtained data indicate that in summer period in a farm located on the flat territory of the Krasnodar region the cattle are influenced by the heat stress. The relationship between the state of moderate heat stress in dairy cattle and the dynamics of a number of indicators characterizing the syndrome of endogenous intoxication of their body was revealed. The increase in the concentration of medium mass molecules (MMM) in healthy livestock was almost two times lower than in animals with fatty hepatosis. The obtained results can serve as a rationale for the development of an effective strategy for pharmacological correction of heat stress in cattle.
\end{abstract}

\section{Introduction}

Global climate warming is one of the main modern challenges for the entire world community. According to scientists, now has been recorded an increase in the average annual temperature of the planet by $1.5^{\circ} \mathrm{C}$, which caused the melting of glaciers and an increase in the level of the World Ocean. In addition to warming, there is an imbalance in all natural systems, leading to the change in precipitation patterns, temperature anomalies and the increase in the frequency of extreme events such as hurricanes, floods and droughts. Climatologists warn that the climate in Russia is warming 2.5 times faster than the planet as a whole $[1,2]$. Thus, in the last decade, an unfavorable combination of an increase in ambient temperature with a decrease in precipitation has been constantly recorded in the flat territories of the Southern Federal District of the Russian Federation.

Climate warming poses a threat to the economy, industry and agriculture. Significant economic losses in the livestock sector can be due to the fact that the highly productive dairy cattle in the summer period are most susceptible to the heat stress, which results in deterioration of animal health and a significant decline in productivity. Heat stress is the result of an imbalance between the flow of heat from the environment and the release of it

* Corresponding author: sever291@,mail.ru 
by the body. Heat stress in cattle can be caused by the high air temperature combined with increased or, conversely, very low humidity, certain features of the technological process of milk production, as well as a decrease in the adaptive potential of the body in the presence of various diseases in animals [3-6].

The severity of the condition of animals under the stress is caused by the severity of dysfunctions of various organs and systems of the body, as well as the degree of development of hypoxia and endotoxicosis. The syndrome of endogenous intoxication is one of the most common in clinical practice and is observed in a wide variety of pathologies. Endogenous intoxication (EI) is a pathophysiological process characterized by the formation and accumulation of various compounds in tissues and body fluids in excessive concentrations or forms that are not characteristic for normal metabolism. Endogenous toxins, resulting from exposure to a known or unknown etiological factor / factors, largely determine the clinical course and outcome of the underlying disease [7-10].

The development and severity of the EI syndrome is evidenced by integral biological tests, among which an important place is given to the determination in biological fluids of medium mass molecules (MMM), characterized by one common property - a molecular weight from 300 to $5000 \mathrm{D}$. The composition of MMM is represented by oligosaccharides, products of protein catabolism, derivatives of glucuronic acids, nucleotides and other substances that themselves can have a damaging and toxic effect on cell membranes, increase vascular permeability and cause tissue hypoxia. It should be noted that the concentration of MMM in the blood plasma reflects the processes of catabolism, and in pathological conditions, the processes of destruction that take place in the cells of the body. A feature of these biomarkers is that they provide an assessment not of any one biochemical or pathophysiological reaction, but cover the whole process. This already allows making conclusions about the state of the complex of biological and biochemical systems of the whole organism [11-15].

The topic of endotoxicosis in various pathological conditions of the human body has been studied and highlighted in the scientific works of many researchers. However, despite the great importance of this problem, there are no studies devoted to determining the role of endogenous intoxication in the pathogenesis of heat stress in cattle.

The aim of this work is to study the level of MMM in the blood of cows under the chronic heat stress.

\section{Materials and Methods}

The studies were carried out on Holstein cows in a livestock farm located on the flat territory of the Krasnodar region in the period from May to July 2020.

In early May, at the ambient temperature recorded in the comfort zone for cattle, two groups of cows, 10 heads each, were formed according to the principle of paired analogs. Group 1 consisted of healthy livestock, and group 2 consisted of animals with liver pathology (fatty hepatosis). The cows were ranked by physiological state (2-3 months of lactation), results of clinical examination, ultrasonography and biochemical blood tests.

The period for the study of pathophysiological changes in the body of cows under the heat stress was determined based on the calculated indicators of the temperature-humidity index (THI) taking into account the average daily temperature and humidity of the environment. The interpretation of the obtained results was based on the parameters of the temperature-humidity index, when: THI $>68$ - mild heat stress; THI $>72$ - moderate heat stress; THI $>80$ - strong heat stress.

The microclimate indicators in the barn were determined at the beginning and at the end of the experiment (the average value was calculated in 3 contiguous days). Samples for studying microbial contamination were taken at three points - at the ends and in the center 
of the room. Temperature, relative humidity and airflow rate were determined using a Testo 410-2 hot-wire anemometer. Concentration of harmful gases was determined using a portable universal gas analyzer UG-2. The level of microbial contamination of the air was determined by sedimentation method.

Blood samples for the research were taken from all cows at the beginning of the experiment (May) and at the end of it (July). Blood was taken from the tail vein of the animals into vacuum tubes in the morning before feeding. Laboratory blood tests were carried out on a Vitalab Selectra Junior automated biochemical analyzer using reagents from ELITech Clinical Systems.

The concentration of MMM in blood serum was determined using the screening method of N.I. Gabrielyan and V.I. Lipatova at three wavelengths $\lambda=237 \mathrm{~nm}$ (MMM 237), $\lambda=254$ $\mathrm{nm}$ (MMM 254) and $\lambda=280 \mathrm{~nm}$ (MMM 280). To register the optical density in the ultraviolet region of the spectrum, an Ecoview UV-1100 spectrophotometer was used. The distribution index (DI) of MMM was calculated using the formula: DI 280/254 = MMM 280 / MMM 254.

Statistical processing of the obtained results was carried out using the Statistica 10 software. Quantitative characteristics were assessed by comparing the mean values of sample populations with the determination of the Student's $t$ - test, the difference in the arithmetic mean was recognized as statistically significant at $\mathrm{p} \leq 0.05$.

\section{Results}

As a result of the studies, it was determined that in the summer period on the flat territory of the Krasnodar region, dairy cattle are influenced by the chronic heat stress, with a predominance of moderate heat stress in terms of severity. At the same time, a constantly high THI was registered in July, with indicators $>72$ in all ten days of the month (Pic. 1).

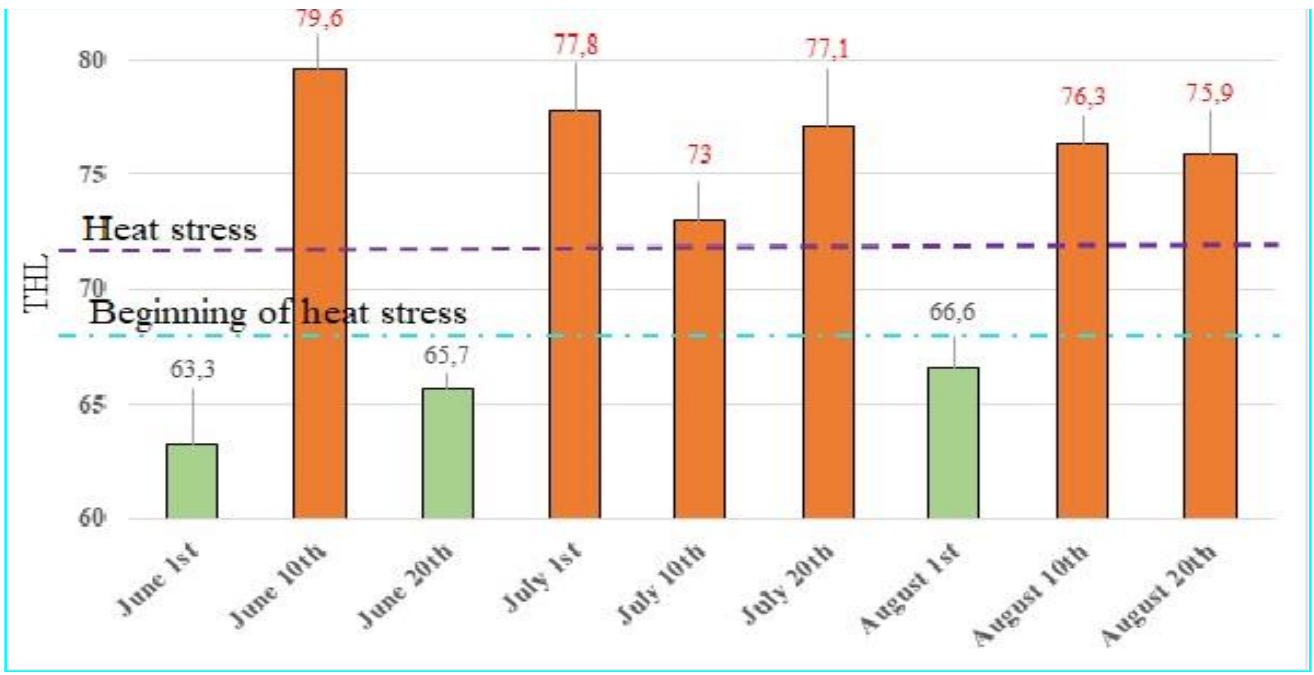

Fig. 1. Dynamics of the temperature and humidity index in the summer months of 2020 in the Krasnodar region.

The results of studying the microclimate parameters of the barn, where the cows participating in the experiment were kept, are presented in Table 1. As can be seen from these data, at the end of July, the THI in the daytime was 77.78 (moderate heat stress), and the airflow speed was $1.73 \pm 0.17 \mathrm{~m} / \mathrm{s}$ (exceeding the maximum permissible indicators for 
the summer season in 2.5 times). In the spring period - early May, the content of ammonia and carbon dioxide in the barn did not exceed the norm, and at the final study, their concentrations were higher than the norm - ammonia by $23.5 \%$, and carbon dioxide - by $45.7 \%$.

Table 1. Dynamics of indicators of the microclimate of the barn.

\begin{tabular}{|l|l|l|l|l|}
\hline \multicolumn{1}{|c|}{ Indicators } & May, 7-9 & $\begin{array}{c}\text { Norm for } \\
\text { the spring } \\
\text { period }\end{array}$ & $\begin{array}{c}\text { July, 27- } \\
\mathbf{2 9}\end{array}$ & $\begin{array}{c}\text { Norm for } \\
\text { the } \\
\text { summer } \\
\text { period }\end{array}$ \\
\hline Temperature, ${ }^{\circ} \mathrm{C}$ & $15.5 \pm 0.5$ & $11.8-14.5$ & $29.1 \pm 1.44$ & $13.3-15.7$ \\
\hline Humidity, \% & $69.3 \pm 1.15$ & $69.6-87.2$ & $56.7 \pm 3.21$ & $65.4-83.7$ \\
\hline THI & 58.81 & $\leq 68$ & 77.78 & $\leq 68$ \\
\hline Airflow speed, m/s & $0.58 \pm 0.09$ & $0.26-0.59$ & $1.73 \pm 0.17$ & $0.31-0.69$ \\
\hline $\begin{array}{l}\text { Concentration: } \\
\text { ammonia, mg / m }{ }^{3}\end{array}$ & $15.2 \pm 1.37$ & $10.7-16.3$ & $23.4 \pm 1.56$ & $10.1-17.9$ \\
\hline carbon dioxide, \% & $0.21 \pm 0.05$ & $0.16-0.23$ & $0.35 \pm 0.09$ & $0.15-0.19$ \\
\hline $\begin{array}{l}\text { Bacterial contamination, } \\
\text { thousand CFU / m3: }\end{array}$ & & $\begin{array}{l}\text { no more } \\
\text { than 70 }\end{array}$ & & $\begin{array}{l}\text { no more } \\
\text { than 70 }\end{array}$ \\
\hline edge of the barn & 23.7 & & 15.6 & \\
\hline center of the barn & 46.9 & & 32.2 & \\
\hline
\end{tabular}

The bacterial contamination of the air in the barn was within normal limits, while the indicators of the total bacterial contamination of the indoor air during the study period varied as follows: the highest level of bacterial contamination was noted in May and amounted to 46.9 thousand CFU / $\mathrm{m}^{3}$ of air (center of the barn), and the lowest level in July was 15.6 thousand $\mathrm{CFU} / \mathrm{m}^{3}$ of air (edge of the barn). In general, the bacterial contamination of the air in the central part of the barn was 2 times higher than in the periphery.

As a result of studying the dynamics of the level of endogenous intoxication (Table 2), it was determined that at the beginning of the experiment the level of MMM of all fractions in the blood serum of cows with liver pathology was higher than in healthy animals. When calculating, the difference was: MMM 237 - 9.9\%; MMM 254 - 14.1\%; MMM 280 $23.4 \%$. To obtain a more complete picture of the development of endotoxicosis, DI 280/254 was calculated, which in general makes it possible to assess the direction of the observed changes in physiological, biochemical and regulatory processes towards pathology or norm and their relationship to each other. Analysis of the distribution index by groups on background studies showed that in animals with liver pathology, its value was higher by $31.8 \%$.

By the end of the experiment, with the development of the heat stress in cows in both groups, MMM indicators increased relative to the background data:

- in group 1 (healthy cows) MMM 237 increased by 5.9\%, MMM 254 increased by $10.8 \%$, MMM 280 increased by $22,2 \%$ and DI $280 / 254$ increased by $12.4 \%$;

- in group 2 (cows with fatty hepatosis) MMM 237 increased by 13.3\%, MMM 254 increased by $21.1 \%$, MSM 280 increased by $35.5 \%$ and DI $280 / 254$ increased by $17.9 \%$.

In general, the obtained results confirm the data that long-term exposure to factors that stress homeostasis translates the body to a lower level of reactivity. Under the stress, the body faces the task of maintaining normal homeostasis and its optimization, but with prolonged exposure to the tissues and biological fluids of the body, an excess of products of normal or impaired metabolism accumulates, which causes the development of endogenous intoxication with an increase in the level of MMM in blood [11, 12] 
Table 2. Dynamics of MMM concentration in the blood serum of cows with the heat stress $(M \pm m$, $\mathrm{n}=10$ )

\begin{tabular}{|l|l|l|l|l|}
\hline \multirow{2}{*}{ Indicators } & \multicolumn{4}{|c|}{ Group } \\
\cline { 2 - 5 } & \multicolumn{2}{|c|}{$1-$ healthy } & \multicolumn{2}{c|}{2 -with hepatopathology } \\
\cline { 2 - 5 } & $\begin{array}{c}\text { Beginning } \\
\text { of } \\
\text { experiment }\end{array}$ & $\begin{array}{c}\text { End of } \\
\text { experiment }\end{array}$ & $\begin{array}{c}\text { Beginning of } \\
\text { experiment }\end{array}$ & $\begin{array}{c}\text { End of } \\
\text { experiment }\end{array}$ \\
\hline MMM 237 nm, AU & $0.755 \pm 0.011$ & $0.802 \pm 0.016$ & $0.830 \pm 0.013$ & $0.957 \pm 0.024$ \\
\hline MMM 254 nm, AU & $0.206 \pm 0.005$ & $0.231 \pm 0.011^{*}$ & $0.235 \pm 0.006$ & $0.298 \pm 0.017^{* *}$ \\
\hline MMM 280 nm, AU & $0.175 \pm 0.009$ & $0.225 \pm 0.014^{*}$ & $0.216 \pm 0.015$ & $0.335 \pm 0.022^{*}$ \\
\hline DI 280/254 nm, AU & 0.85 & 0.97 & 0.92 & 1.12 \\
\hline
\end{tabular}

Note: differences are significant $* \mathrm{p} \leq 0.05,{ }^{* *} \mathrm{p} \leq 0.01$ in relation to the background data

\section{Conclusion}

Thus, it was revealed that in the summer period in the farms located on the flat territory of the Krasnodar region, cattle are influenced by the heat stress. The relationship between the state of moderate heat stress in dairy cattle and the dynamics of a number of indicators characterizing the development of the syndrome of endogenous intoxication of their body has been determined. The intensity of the increase in the concentration of MMM in the blood serum in healthy livestock was almost 2 times lower than in animals with fatty hepatosis. Perhaps this pattern is explained by the fact that in cows with the liver diseases have the insufficient level of adaptive-compensatory reactions of the body and with the prolonged stress load there is a significant increase in the integral indicators of endotoxicosis, which may be an additional cause of impairment of various body functions.

The obtained results can serve as a rationale for the development of an effective strategy for pharmacological correction of the heat stress in cattle.

The study was supported by the Russian Foundation for Basic Research as part of a scientific project № 20-316-90009.

\section{References}

1. Q Sun., C. Miao, M. Hanel, et al., Environ Int., 128, 125-136 (2019) doi: 10.1016/j.envint.2019.04.025

2. R.A. Betts, L. Alfieri, C. Bradshaw et al., Philos Trans A Math Phys Eng Sci., 13, 376 (2018) doi: 10.1098/rsta.2016.0452

3. R. Boni, Mol Reprod, 86 (10), 1307-1323 (2019) doi: 10.1002/mrd.23123

4. Z. Roth, Annu Rev Anim Biosci., 5, 151-170 (2017) doi: 10.1146/annurev-animal022516-022849

5. M. Bagath, G. Krishnan, C. Devaraj et al., Res Vet Sci., 126, 94-102 (2019) doi: 10.1016/j.rvsc.2019.08.011

6. I. Veissier, E. Van Laer, R. Palme et al., Int J Biometeorol., 62 (4), $585-595$ (2018) doi: 10.1007/s00484-017-1468-0

7. M.F. Zarivchatsky, S.N. Styazhkina, Izhevsk, 140 (2013)

8. M.P. Semenenko, E.V. Kuzminova, E.V. Tyapkina, A.A. Abramov, K.A. Semenenko, J. of Pharmac. Sci. and Res. (JPSR), 9(9), 1573-1575 (2017)

9. V.G. Skopichev, L.V. Zhichkina, O.O. Smirnova, St. Petersburg: “Anons”, 30 (2010) 
10. V.I. Sidelnikova, A.E. Chernitskiy, M.I. Retskiy, Agricultural biology, 50 (2), 152-161 (2015) doi: 10.15389/agrobiology.2015.2.152rus

11. S.A. Abdelnour, M.E. Abd El-Hack, A.F. Khafaga et al., J Therm Biol., 79, 120-134 (2019) doi: 10.1016/j.jtherbio.2018.12.013

12. G. Venkatachalam, U. Surana, M.-V. Clément, Nucleic Acids Research, 45(18), 10564-10582 (2017) https://doi.org/10.1093/nar/gkx684

13. A. Gomez-Zavaglia, J.C. Mejuto, J. Simal-Gandara, Food Research International, 134, 109256 (2020) 10.1016/j.foodres.2020.109256

14. N. Saipin, S. Semsirmboon, R. Rungsiwiwut, S. Thammacharoen, Journal of Thermal Biology, 94, 102783 (2020) 10.1016/j.jtherbio.2020.102783

15. D. Renaudeau, A. Collin, S. Yahav, V. De asilio, J.L. Gourdine, R.J. Collier, Animal, 6, 707-728 (2012) 10.1017/s1751731111002448 